\title{
Country Codes
}

$\begin{array}{ll}\begin{array}{l}\text { Country } \\ \text { code }\end{array} & \text { Country } \\ \text { AT } & \text { Austria } \\ \text { BE } & \text { Belgium } \\ \text { BG } & \text { Bulgaria } \\ \text { CH } & \text { Switzerland } \\ \text { CY } & \text { Cyprus } \\ & \\ \text { CZ } & \text { Czech Republic } \\ \text { DE } & \text { Germany } \\ \text { DK } & \text { Denmark } \\ \text { EE } & \text { Estonia } \\ \text { ES } & \text { Spain } \\ & \\ \text { FI } & \text { Finland } \\ \text { FR } & \text { France } \\ \text { GB } & \text { Great Britain (United Kingdom) } \\ \text { GR } & \text { Greece } \\ \text { HR } & \text { Croatia } \\ & \\ \text { HU } & \text { Hungary } \\ \text { IS } & \text { Iceland } \\ \text { IE } & \text { Ireland } \\ \text { IL } & \text { Israel } \\ \text { IT } & \text { Italy } \\ & \\ \text { LT } & \text { Lithuania } \\ \text { LV } & \text { Latvia } \\ \text { NL } & \text { Netherlands } \\ \text { NO } & \text { Norway } \\ \text { PL } & \text { Poland } \\ & \\ & \\ & \\ & \\ & \end{array}$


xviii Welfare State Legitimacy in Times of Crisis and Austerity

Country

code Country

PT Portugal

RO Romania

RU Russian Federation

SE Sweden

SK Slovakia

SI Slovenia

TU Turkey

UA Ukraine

UK United Kingdom (Great Britain) 